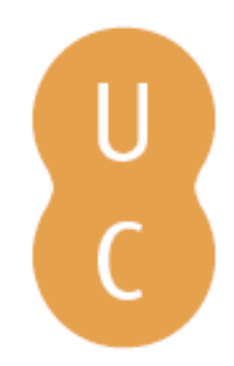

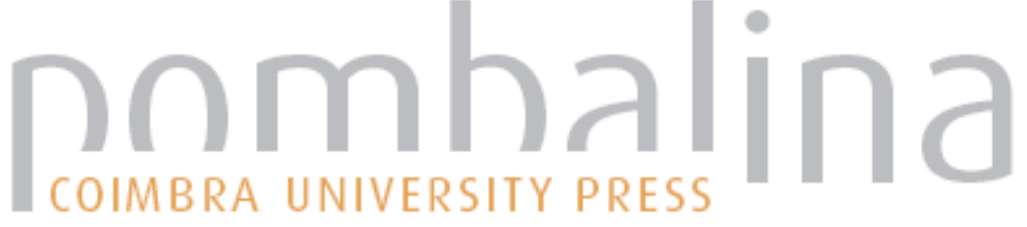

\section{História e direito: perspectivas de um combate necessário}

\author{
Autor(es): $\quad$ Chorão, Luís Bigotte
}

Publicado por: Imprensa da Universidade de Coimbra

URL

persistente: $\quad$ URI:http://hdl.handle.net/10316.2/31601

DOI: $\quad$ DOI:http://dx.doi.org/10.14195/978-989-26-0199-1_12

Accessed : $\quad$ 26-Apr-2023 12:35:21

A navegação consulta e descarregamento dos títulos inseridos nas Bibliotecas Digitais UC Digitalis, UC Pombalina e UC Impactum, pressupõem a aceitação plena e sem reservas dos Termos e Condições de Uso destas Bibliotecas Digitais, disponíveis em https://digitalis.uc.pt/pt-pt/termos.

Conforme exposto nos referidos Termos e Condições de Uso, o descarregamento de títulos de acesso restrito requer uma licença válida de autorização devendo o utilizador aceder ao(s) documento(s) a partir de um endereço de IP da instituição detentora da supramencionada licença.

Ao utilizador é apenas permitido o descarregamento para uso pessoal, pelo que o emprego do(s) título(s) descarregado(s) para outro fim, designadamente comercial, carece de autorização do respetivo autor ou editor da obra.

Na medida em que todas as obras da UC Digitalis se encontram protegidas pelo Código do Direito de Autor e Direitos Conexos e demais legislação aplicável, toda a cópia, parcial ou total, deste documento, nos casos em que é legalmente admitida, deverá conter ou fazer-se acompanhar por este aviso.

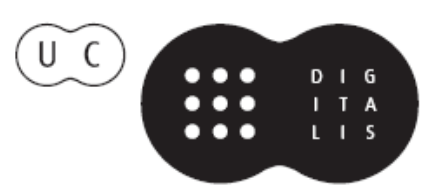


Maria Manuela Tavares Ribeiro

Coordenação

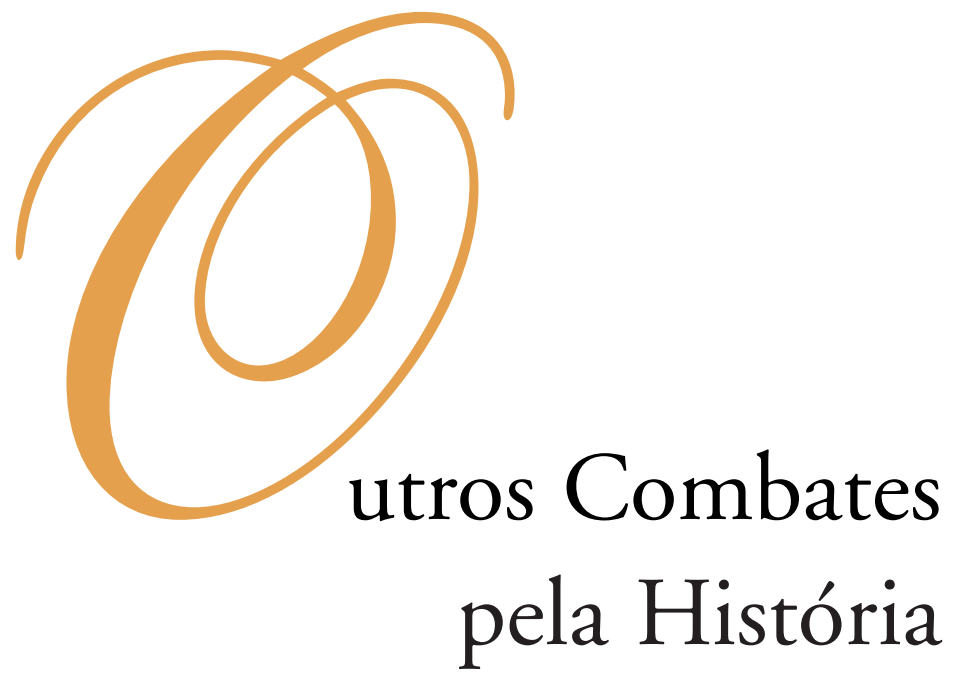




\section{COORDENAÇĀO EDITORIAL}

Imprensa da Universidade de Coimbra

Email: imprensauc@ci.uc.pt

URL: http://www.uc.pt/imprensa_uc

Vendas online: http://livrariadaimprensa.com

\section{CONCEPÇÃO GRÁFICA}

António Barros

\section{ORgANIZAÇĀO DOS TEXTOS}

Isabel Maria Luciano

Marlene Taveira

PRÉ-IMPRESSÃO

António Resende

Imprensa da Universidade de Coimbra

EXECUÇÃO GRÁFICA

SerSilito • Maia

ISBN

978-989-26-0041-3

DEPósito LEGAL

OBRA PUBLICADA COM O APOIO DE:

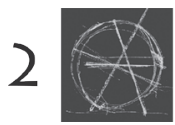

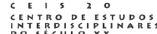

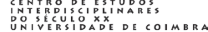

FCT Fundação para a Ciência e a Tecnologia

MINISTÉRIO DA CIÊNCIA, TECNOLOGIA E ENSINO SUPERIOR Portugal

Programa Operacional Ciência, Tecnologia, INOVAÇĀo DO QUADRo COMUNITÁRIO DE APOIO III

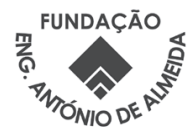

C JULHO 2010, IMPRENSA DA UNIVERSIDADE DE COIMBRA 
Maria Manuela Tavares Ribeiro

Coordenação

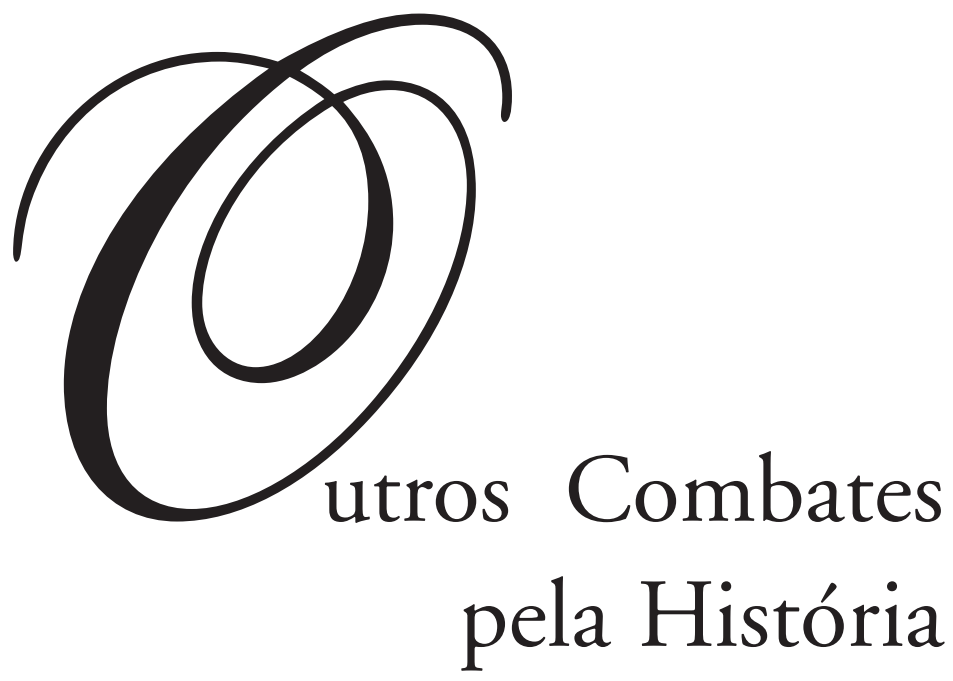

- colmbra 2010 
História e Política 


\section{Luís Bigotte Chorão}

\section{História E DIREITO:}

\section{PERSPECTIVAS DE UM COMBATE NECESSÁRIO}

Quero antes de mais agradecer à Senhora Doutora Maria Manuela Tavares Ribeiro, o convite para participar neste Colóquio, cujo título sugestivo e interpelante assinala inspiradamente o décimo aniversário do CEIS20, e a justa homenagem que se presta ao Senhor Doutor Reis Torgal — um Homem de causas e de combates —, desde logo de combates pela História.

É com o maior gosto que me associo a esta iniciativa.

Cumprimento muito cordialmente o Senhor Doutor Reis Torgal e todos quantos, com ele, tornaram possível a realidade que é hoje o CEIS20, e saúdo, bem assim, os participantes no Colóquio, nomeadamente os membros ilustres do painel que tenho a honra de integrar.

Porque o tempo urge, entro de imediato no tema da minha intervenção na qual pretendo apresentar uma breve reflexão em torno da questão essencial das relações entre a história e o direito.

Perante este binómio — história e direito —, têm-se debatido qual dos dois termos constitui o elemento regente e qual o elemento regido ${ }^{1}$. A resposta a esta interrogação é condicionante, obviamente, de desenvolvimentos e conclusões da presente reflexão.

Sendo o direito, como é, um fenómeno cultural, entre outros, situado e desenvolvido historicamente, parece dever entender-se que a prioridade ontológica pertencerá — no referido binómio — à história, competindo à história do direito, precisamente, a análise do processo histórico-cultural do jurídico, com todos os seus laços de interdependência com outros fenómenos culturais.

Quer isto dizer, em suma, que a compreensão do direito como facto social complexo desenvolvido no tempo, através de multiformes concretizações, não pode dispensar-se da consideração, na mais ampla perspectiva possível, das realidades pré-jurídicas, extra-jurídicas e até meta-jurídicas, que de algum modo condicionam e

${ }^{1}$ Cf. sobre o tema, Helmut Coing, Las tareas del historiador del derecho (reflexiones metodológicas), Traducción de Antonio Merchán, Sevilha, Publicaciones de la Universidad de Sevilla, 1977, pp. 35-41 e David Torres Sanz, Historia del Derecho: Bases para un Concepto, Valladolid, Universidad de Valladolid, 1986, p. 9. 
fundamentam o direito. Só desse modo, a investigação historiográfica cumprirá o seu papel de revelação do processo de desenvolvimento do direito no contexto cultural, e de discernimento das linhas de continuidade e descontinuidade ${ }^{2}$, de fidelidade à tradição e de ruptura, na dinâmica histórica. Ou seja, o historiador do direito tem de manter-se permanentemente atento ao sentido que assumem os fenómenos jurídicos na sua ligação com os diversos factores humanos e sociais que com ele se conexionam. Tal o caso mormente dos factores políticos, que, de modo muito íntimo, se ligam ao direito, servindo-se dele para a consecução dos fins naturais da sociedade política, ou, porventura, instrumentalizando-o ideologicamente, em função de opções concretas historicamente identificáveis ${ }^{3}$.

É certo que, assim perspectivada, a história do direito, sem prejuízo do seu específico interesse jurídico, desempenha, um papel fundamental na amplificação da consciência histórica e de valorização da ciência histórica. Essa missão é ressaltada, entre outros, por Bruno Paradisi, figura notável de jus-historiador e metodólogo.

Ora, exactamente esse objectivo de amplificação da consciência histórica, e consequentemente jurídica, está pressuposto na sugestão de que um dos combates pela história se pode e deve fazer a partir de uma mais próxima colaboração entre historiadores e juristas historiadores. É este um aspecto que eu gostaria de assinalar de forma especial, servindo-me nesta circunstância do autorizado testemunho de Michael Stolleis. Numa comunicação à Universidade de Liubliana, em Maio de 2007, formulou um voto que justifica recordar aqui:

«Mon $[\ldots]$ vœu concerne la séparation entre les sciences historiques et l'histoire du droit. On doit dépasser ce stade. L'histoire du droit est sans aucun doute sur le plan de la méthode une spécialité historique. Son objet est le mode fonctionnel du

2 Cf. Giovanni Cassandro, Sul Problema della Continuità Storica, Estratto, Annali di Storia del Diritto, Ano XIV-XVII, 1970-1973 e Hans Thieme, La Continuidad y la Descontinuidad en la Historia del Derecho, Conferencia pronunciada en la Academia Matritense de Notariado el dia 14 de Maio de 1974 (Publicada en el Tomo XX de "Anales de la Academia Matritense del Notariado»), onde a dado passo refere que a racionalização, juntamente com a unificação, a formação de grandes famílias jurídicas homogéneas e outros factores contribuiram para que se afirmasse a descontinuidade do direito, o que leva Thieme a afirmar que a história das ideias rege a história do direito. Como ensinou Paradisi, Apologia della Storia Giuridica, Bolonha, IL Mulino, 1973, pp. 269-270, a continuidade do direito não é mais do que um aspecto particular do problema geral da continuidade das condiçôes sociais, da autoridade do Estado, da tradição doutrinal, enfim, resultado do desenvolvimento da história que se reflecte no desenvolvimento do direito e que é ao mesmo tempo por ele influenciado. Tem natural pertinência neste domínio a questão formulada por Fernando Catroga, Caminhos do Fim da História, Colecção Caminhos, Coimbra, Quarteto, 2003, p. 156: «Poder-se-á perguntar (...) se conceitos como descontinuidade, fragmentação, policentrismo, acaso, subjectividade, compreensão, poderão, só por si, ser pensados e aplicados, a um mundo crescentemente relacional e comunicacional (Habermas), sem a sua geminação com os de universalidade, continuidade, totalidade, centralidade, necessidade, objectividade».

${ }^{3}$ Helmut Coing, Las tareas... cit., p. 51, nota que a compreensão de um ordenamento jurídico do passado tem de partir dos seus próprios condicionamentos, quer dizer, como um problema de ordenação da sua própria época. Sendo assim, hermeneuticamente essa compreensão está ligada de forma inseparável da compreensão dos seus condicionamentos históricos, pelo que concluía Coing, "só partindo desses condicionamentos pode o historiador conhecer bem os problemas aos quais o ordenamento jurídico por ele investigado tentou dar uma resposta». 
droit dans les anciennes sociétés. Les frontières entre historiens et historiens du droit sont absurdes, elles sont même dommageables. Le dialogue fonctionne de manière inégale, quelquefois excellemment, mais quelquefois il est plutôt marqué par le non-dit, l'éloignement et la méconnaissance des écrits spécialisés. Mais cela devrait s'améliorer dans le cadre européen ${ }^{4}$.

Existe, é certo, um esforço a fazer por parte de todos. Aos historiadores juristas deve caber, pelo seu exemplo, quer dizer, não desprezando o que outros saberes lhe fornecem de útil, contribuir para desacantonar alguma historiografia da reclusão no seu universo e que anda de costas voltadas para a realidade do jurídico enquanto fenómeno histórico. Aos historiadores ditos gerais, por seu lado, cabe certamente a afirmação de uma perspectiva inclusiva que sirva a superar o que já entre nós sugestivamente qualificou Rui Figueiredo Marcos de «concepção insular do direito na história " 5 . Isto, para que possam abater-se as absurdas e prejudiciais fronteiras de que nos fala Stolleis, cumprindo-se, a final, em nome da História, a imperiosa missão do trabalho em cooperação científica estreita entre historiadores e juristas-historiadores no quadro de uma saudável interdisciplinariedade.

Pela minha parte, e em coerência de pensamento, devo afirmar que me incluo entre os que não se conformam com uma história do direito esgotada num dogmatismo normativista de mero interesse formalístico e sistemático, aprisionada por um sistema de conceitos auto-suficientes, como se a história jurídica, se pudesse ou devesse fechar ao atendimento e compreensão de dados, que, não sendo jurídicos, foram geralmente — como já assinalei —, os modeladores do direito. E, além disso, também, aos contributos que permanentemente são apresentados noutros domínios científicos, que não podem deixar de considerar-se no nosso campo de investigação, cumprindo assinalar aqui as virtualidades da multidisciplinariedade, cuja valorização constitui marca do CEIS20, acolhida, aliás, significativamente, na sua designação.

Mas devo acrescentar que sou sensível à chamada de atenção de Tomás y Valiente, que embora defendendo uma concepção integradora da história do direito na história total, sustentava que essa integração não podia consistir numa mera justaposição, juntamente com outros ramos da historiografia, nem em prejuízo da «especificidade» do objecto e dos métodos da história do direito $^{6}$.

Uma coisa é certa, o direito constitui um aspecto da cultura social que por definição constitui uma totalidade. Como foi justamente lembrado por Rui Figueiredo Marcos, «o direito não irrompe por actos solitários de génio, nem desaparece, fugidiamente

\footnotetext{
${ }^{4}$ Cf. Michael Stolleis, «Histoire du droit européene, toujour à l'etat de projet?» http://www.clio@themis. com.

5 Cf. Rui Figueiredo Marcos, A História do Direito e o seu Ensino na Escola de Coimbra, Coimbra, Almedina, 2008, p. 24.

${ }^{6}$ Cf. Francisco Tomás y Valiente, "Historia del Derecho e Historia" in Once ensayos sobre la Historia, Madrid, Fundación Juan March, Rioduero, 1976, pp. 161-181 e Obras Completas, IV, Madrid, Centro de Estudios Políticos y Constitucionales, 1997, p. 3289. Observa António Pedro Barbas Homem, História do Pensamento Jurídico, Relatório, Revista da Faculdade de Direito da Universidade de Lisboa, Suplemento, Coimbra, Coimbra Editora, 2003, p. 54, que «apenas um jurista familiarizado com os conceitos, as técnicas e o sentido prático do direito pode entender as ordens jurídicas do passado».
} 
na noite do acaso. Insere-se sempre num certo contexto histórico constituinte e reconstituinte. A própria natureza do direito reclama que se entenda vinculado à existência cultural e histórica do homem» ${ }^{7}$.

Ora, se o estudo global de um complexo sócio-cultural pretérito constitui um estudo de carácter histórico, não parece possível, nem admissível, que o estudo sectorializado de tal complexo possa qualificar-se de maneira diferente, quer dizer, também terá natureza histórica, pelo que a história do direito não pode ser senão uma história especializada ou um ramo da história global.

Estas consideraçôes sobre a relação da história com o direito suscitam uma outra reflexão, a reflexão sobre o conceito e o método da historiografia do direito e as suas relações com a dogmática jurídica.

A discussão gerada em torno da problemática metodológica foi suscitada pelo sentimento de envelhecimento e estagnação da historiografia jurídica positivista, caracterizada pelo seu mais que prevalente interesse medievístico ${ }^{8}$ e pelo cepticismo quanto à consagração da contemporaneidade como objecto de investigação, ao qual andava ligado o preconceito em relação a certas fontes, para as quais se olhava com desdém, e para temas logo desvalorizados pelo sua época ou/e pelo seu conteúdo, como se a proximidade temporal fosse incompatível com a dignidade científica, ou certos géneros (v. g. o biográfico) estivessem condenados no domínio histórico-jurídico por uma como que inevitável ausência de densidade historiográfica ou de substantividade jurídica. A este propósito vale por certo a pena lembrar a importância dos estudos biográficos na reconstituição do passado; como ensinou Paradisi, «l'essere individuale entra nella storia soltanto attraverso la sua vita relazionale. E la storia, la storia nel suo più genuino e profondo significato, esiste soltanto come storia del rapporto dell'uomo com gli altri uomini»?

Acusando-a de negar liberdade criativa ao historiador, Francesco Calasso denunciou a crise da historiografia jurídica positivista, crise essa que haveria de propiciar motivaçóes renovadoras nos planos conceptual e metodológico, que tiveram expressão na obra,

\footnotetext{
7 Cf. Rui Figueiredo Marcos, A História do Direito... cit.., p. 9. Convirá a este propósito recordar que Caeiro da Mata ao incumbir-se do elogio de Marnoco e Sousa, traçou um quadro negro sobre a situação dos estudos históricos e histórico-jurídicos em Portugal, cuja metodologia lhe sugeriu uma crítica incisiva cuja pertinência viria a ser amplamente demonstrada. Considerando limitado ao trabalho preparatório da crítica documentaria o estudo histórico do direito, Caeiro da Mata, censurava: «De facto, uma vez apreciado o valor e o conteúdo da fonte, a história do direito é tratada pela generalidade dos historiógrafos como uma cronologia das sucessivas modificações das normas, dos princípios reguladores das diversas matérias, abstraindo-se por completo da análise da íntima estrutura das instituições, das relações entre as várias instituiçōes, e entre o fenómeno jurídico e outros fenómenos sociais, como o económico, o religioso, o moral, o político». Ora, concluía Caeiro da Mata, era «útil e até indispensável» o trabalho de «reconstrução das fontes" e a "crítica dos textos», mas tal não podia constituir «o temo dos estudos históricos» (cf. Caeiro da Mata, "O Professor Marnoco e Sousa e o estudo da história do direito», in Boletim da Faculdade de Direito da Universidade de Coimbra, Ano II, Coimbra, Imprensa da Universidade, 1915-1916, pp. 366-367).

${ }^{8}$ António Manuel Hespanha, A História do Direito na História Social, Colecção Movimento 25, Lisboa, Livros Horizonte, 1978, p. 13, observaria que em Portugal «as famosae quaestiones da história do direito não se situaram para cá do termo da Idade Média (...) e se encerraram nos estreitos limites de um debate de alta erudição".

${ }^{9}$ Cf. Bruno Paradisi, Apologia... cit., p. 8 e 268.
} 
entre muitos outros, de Bruno Paradisi. A edição da sua Apologia della Storia Giuridica, em 1973, suscitou uma revisitação do pensamento de Paradisi. Em França J. Gaudemet dedicou atenção à Apologia nas páginas da Revue Historique de Droit Français et Etranger ${ }^{10}$, em Espanha, Alfonso Garcia Gallo e Álvaro D’Ors apreciaram-na no Anuario de Historia del Derecho Español ${ }^{11}$, em Itália, Luigi Bagolini nos Quaderni Fiorentini ${ }^{12}$.

Diferentemente, porém, da interpretação de D’Ors, a história do direito não foi para Paradisi «antes de tudo história cultural e social» ${ }^{13}$. O que o Mestre italiano defendeu, com uma coerência que já se assinalou, foi a radical historicidade do direito ${ }^{14}$, da qual resulta, consequentemente, que o ponto de vista do historiador do direito não esteja no direito, mas fora dele, no imenso campo da história que necessariamente o compreende. Daqui não se infere, claro está, que o direito deixe de constituir o objecto imediato e específico da história jurídica, só que o direito é expressão do pensamento, de sentimentos e interesses humanos que o criam, modificam e interpretam, donde a conclusão de Bruno Paradisi de acordo com a qual aquela história particular não pode fazer-se senão pensando a história do direito a partir da interpretação dos factos jurídicos inseridos numa visão da fenomenologia histórica na sua totalidade ${ }^{15}$.

Tal como escreveu:

«Si avrà dunque vera e piena storia giuridica solatanto quando alla storia di quanto è sociale, cioè al suo ripensamento ed alla sua esposizione, si pervenga mediante una visione completa della realtà, e per questo attraverso un pieno intendimento di quanto l'individuo, che è cosi intimamente ed indissolubilmente legato alla società, há operato, creato o distrutto per se stesso e per quest'ultima» ${ }^{16}$.

10 Cf. Revue Historique de Droit Français et Étranger, Extrait du Vol. 53, 1975, pp. 84-85.

${ }^{11}$ Cf. Alfonso Garcia-Gallo, "Cuestiones de historiografia jurídica» in Anuario de Historia del Derecho Español, 44, 1974, pp. 741-752 e Alvaro D’Ors, «Sobre historiografia juridica» in Anuario de historia del Derecho Español, 47, 1977, pp. 799-812.

12 Cf. Quaderni Fiorentini per la storia del pensiero giuridico moderno, 3-4 (1974-75), Il «Socialismo giuridico", Ipotesi e letture, Tomo II, pp. 712-722.

13 Cf. Alvaro D’Ors, «Sobre historiografia... cit., p. 803.

${ }^{14}$ Cf. Francesco Calasso, «Storicità del diritto e Scienza del diritto» in Storicità del Diritto, Civiltà del Diritto, 15, Milão, Giuffrè, 1966, pp. 175-199. Tal com afirma José Artur Duarte Nogueira, Objecto e Método na História do Direito (Algumas Consideraçôes), Separata de Estudos em Homenagem ao Prof. Raul Ventura, Edição da Faculdade de Direito da Universidade de Lisboa, Coimbra, Coimbra Editora, 2003, p. 245, «falar-se em historicidade do direito significa ter consciência que a ordem jurídica se realiza na história, que está concretamente relacionada com um determinado meio social, político, económico e cultural, nele nasce e se desenvolve, É, pois, muito variável e epocal, daqui derivando que o particularismo da experiência jurídica só se revelará em todas as suas facetas, através da concreta apreensão histórica da sua realização».

15 Cf. Bruno Paradisi, Apologia della Storia Giuridica, Bolonha, IL Mulino, 1973, pp. 266-267. Ainda, Luigi Raggi, Diritto e Storiografia, A proposito di alcune recenti discussioni, Estratto da B.I.D.R «Vittorio Scialoja», Terza Serie, Milão, Dott. A. Giuffrè editore, 1964.

16 Idem, p. 54. 
Um estudo que tenho em curso recorda-me o acerto desta lição de Paradisi. Com efeito, verifico a cada passo a insuficiência explicativa, e portanto o logro historiográfico, de um critério de investigação, de um critério metodológico, que exclusivamente me centrasse no direito - no caso em concreto na legislação judiciária do nosso século $\mathrm{XX}^{17}$ —, sem que me permitisse olhar essa realidade [normativa], sujeita a modificações, as mais diversas, desde fora, quer dizer desde fora do direito. Isto para apreender as razões extra-jurídicas que estiveram na base das decisões legislativas, as decisões normativas, os ideais axiológico-normativos ${ }^{18}$ que conduziram àquela realidade em estudo, cujo registo nas páginas do jornal oficial não as torna auto-explicativas.

Francesco Calasso, a quem já me referi, tratando do objecto da história do direito, e distinguindo o direito objectivo ou norma agendi, do direito subjectivo ou facultas agendi, interrogou-se, assim:

«Di quale diritto facciamo la storia? Si suole comunemente rispondere: del diritto oggetivo. Legi, consuetudini, e, per il contenuto normativo che puo essere loro congiunto, giurisprudenza e dottrina giuridica, sono oggetto di storia in quanto fonti produttive, immediatamente o mediatamente, di regole di condotta dei soggetti di un determinato ordinamento giuridico».

Porém, afirmava aquele professor:

«Ma anche questa risposta non dice tutto. All'occhio dello storico, le normae agendi non esauriscono tutta la realtà del fenomeno guiridico: esse rientrano nella categoria più vasta delle norme sociali, in quanto regolano (como quelle politiche, economiche, di convenienza ecc., e a differenza di quelle etiche o religiose) la condotta dell'homo socius, dell'uomo cioè che vive e opera in rapporto con altri uomini, e presuppongono quindi una societas, vale a dire un' organizzazione, all'interno della quale esse hanno valore e dalla quale sono poste: ubi societas, ibi ius» ${ }^{19}$.

Questão que por essencial tanto à historiografia jurídica como à ciência do direito foi exemplarmente elucidada pelo ilustre professor italiano prende-se com a relação entre história e dogma jurídico. Para Paradisi entre dogma e história, como entre

17 Tal como ensinou Paradisi, Apologia ... cit., p. 266, «la storia del diritto non è soltanto ricerca di antecedenti legislativi o di sviluppi giurisprudenziale, mà è, in primo luogo, la ricerca del vincolo che unisce il diritto all'epoca sua».

18 António Manuel Hespanha, O Direito e a História, Os caminhos de uma história renovada das realidades jurídicas, Separata da Revista de Direito e de Estudos Sociais, ano XVII, n. ${ }^{\text {os }} 2-4$, Coimbra, 1971, p. 48, justamente notou: "o decisivo no direito não são as normas, mas as intenções normativas nelas plasmadas, os ideais axiológico-normativos que, pela sua observação, se pretende realizar. Esses sim, esses constituem o fundamental do direito, assim se compreendendo que, para respeitar o direito, se possa ir além da lei ou mesmo contra a lei».

19 Cf. Francesco Calasso, Medio Evo del Diritto, I - Le Fonti, Milão, Dott. A. Giuffrè - Editore, 1954, pp. 26-27. Sobre a perspectiva de Calasso, cf. v.g., Antonio Marongiu, Francesco Calasso e la metodologia della storia del diritto, Estrato da Nuova Rivista Storica, Ano XLIX, Fasc. III-IV, 1965, pp. 371-384 e Marco Cardinale, La Storia del Diritto tra Positivismo e Idealismo: Dai Prodromi Gentiliani della polémica"BonfanteCroce» al Metodo Storiografico di Francesco Calasso, Estrato da "Apollinaris», LIX, 1986, pp. 279-302. 
dogma jurídico e história jurídica, não existe unicamente diversidade, mas uma divergência essencial e uma oposição irredutível ${ }^{20}$. É nessa oposição que se funda a coerência e verdadeiramente também a utilidade da historiografia do direito na medida em que ela constitui uma interpretação não dogmática da natureza e do valor do dogma, no qual não pode ver uma lógica abstracta, válida em si mesma, mas uma lógica que constitui ela mesma um facto histórico, colocado no plano de todos os outros factos da história. A perspectiva de Paradisi denunciava, assim, o pensamento de, entre outros, Heinrich Brunner o qual sustentara que para a história do direito era matéria morta toda a que não pudesse conceber-se dogmaticamente ${ }^{21}$.

Superada a radical antinomia entre história e direito, que assentava em pressupostos conceptuais e metodológicos sobre a história e o direito já ultrapassados, impõe-se para concretização do objectivo assinalado a convergência dos investigadores, com respeito e valorização da autonomia dos seus saberes próprios.

Para essa finalidade não pode deixar de concorrer no domínio da investigação histórico-jurídica a consagração de um conceito de fontes da investigação necessariamente amplo, intencionalizado a superar o risco que Wieacker assinalou, qual era o que em sua opiniāo resultava da tendência do historiador do direito para «uma compreensão autoritariamente limitadora das suas fontes históricas» 22 . Essa constatação levaria o mesmo autor a afirmar que constituía «uma tarefa da história do direito libertar-se destas tendências e aproximar cada vez mais a sua exposição, através da inclusão contínua de novas camadas de experiência histórica, da realidade histórica individual» ${ }^{23}$. Entre nós, Martim de Albuquerque também defendeu, em alternativa à proposta metodológica (spezielle Verknupfung) de Helmut Coing ${ }^{24}$, o recurso à

20 Cf. Bruno Paradisi, Apologia... cit., p. 261.

21 Idem, p. 61 e ss. Ainda Rui Figueiredo Marcos, A História do Direito... cit., p. 17 (nota 25). Entre nós, Cabral de Moncada, «O problema metodológico na ciência da história do direito português» in Estudos de História do Direito, volume II, Acta Universitatis Conimbrigensis, Coimbra, Universidade de Coimbra, 1949, p. 206 e ss., defendia que o jus-historiador devia «sobretudo orientar a sua actividade de investigação no sentido da caracterização e relacionação das formas e instituições jurídicas, como conceitos construtivos do espírito e elementos de um sistema de ideias e de crenças, precipitados nos factos, que são para ele justamente aquilo a que se chama direito". E acrescentava ainda aquele professor, sublinhando o que em seu entender constituíam as diferentes missões dos historiadores gerais e do direito, que a estes últimos importava «apenas reconstituir os diversos sistemas jurídicos que existiram no passado, fixá-los e explicá-los», mas, «sem sair do seu específico campo jurídico e, como consequência, buscando surpreender e determinar aí as relaçōes de natureza mais do que lógica, espiritual, entre os próprios factos e conceitos jurídicos entre si, e não as relações sociológicas, genéticas, entre eles e os outros factos humanos e sociais». A posição assim definida por Moncada assentou expressamente numa referência a Emílio Lask que lembrara que Arnold e Ihering tinham chamado a atenção "para o facto de a história jurídica ou haver de estar exclusivamente ao serviço da dogmática do direito conservando a natureza de um disciplina jurídica, ou não poder fugir à tendência para só ver no direito e nas suas abstracções um facto social em conexão com a totalidade da vida", tendo ainda sido assinalados os nomes de Brunner, Below e Amira como partidários da mesma orientação, que mereceu a fundamentada e certeira denúncia de Bruno Paradisi.

22 Cf. Franz Wieacker, História do Direito Privado Moderno, Tradução de A. M. Botelho Hespanha, Lisboa, Fundação Calouste Gulbenkian, 1980, p. 6 (nota 14).

23 Idem, ibidem.

${ }^{24}$ Cf. Helmut Coing, Las tareas... cit., pp. 60-61. 
"pluralidade de fontes» na sua «multiplicidade e heterogeneidade» ${ }^{25}$, que, sendo ampla, consente ao jus-historiador uma abordagem empírica do objecto da sua investigação, consentindo-lhe liberdade criativa, sem o eximir de observar os particularismos próprios da sua arte, necessariamente determinados pela sua formação e cultura jurídicas.

A emergência da historiografia do Direito da contemporaneidade constitui um acontecimento que desejo pôr em relevo, até porque constitui no quadro geral dos estudos históricos uma tendência recente que vai abrindo perspectivas de diálogo científico entre historiadores e juristas historiadores. Aliás, a produção científica, já notável neste domínio, é indicativa do atractivo que exerce a matéria objecto de investigação que tem mobilizado investigadores com formações diversas e nalguns casos até, valha a verdade, e revele-se-me a franqueza, investigadores sem formação nenhuma...

Centrando-nos, pois, na história contemporânea, atente-se, a título de exemplo, na multiplicidade de estudos relativos às experiências totalitárias e autoritárias - e às suas implicações e expressôes jurídicas —, que tiveram como palco a Europa no século XX. Campo muito fértil de produção científica, esse domínio - é interessante verificá-lo —, merece a atenção de historiadores do direito, os quais, a partir de trabalhos pioneiros de Paolo Ungari em Itália ${ }^{26}$ e de Michael Stolleis na Alemanha ${ }^{27}$, nos anos sessenta e setenta do século passado, têm contribuído no seu conjunto para superar o "medo» da contemporaneidade.

A consulta da muito útil Bibliografia Orientativa del Fascismo, de 1991, dirigida por Renzo De Felice, demonstra claramente a insipiência dos estudos especifícamente no domínio da "cultura jurídica» ${ }^{28}$, em contraste com a demais investigação sobre o fascismo. O estado da ciência àquela data - prova da emergência da contemporaneidade — não é já o dos nossos dias, principalmente depois dos contributos de figuras maiores da historiografia jurídica italiana, entre as quais cumpre salientar o prestigiado nome de Paolo Grossi.

Conforme notou o jus-historiador Aldo Mazzacane, o dado novo e mais evidente que emerge da historiografia jurídica italiana mais recente «é representado pela notá-

25 Cf. Martim de Albuquerque, História das Instituiçôes, Relatório sobre o Programa, Conteuido e Métodos de Ensino, Lisboa, Separata da Revista da Faculdade de Direito, ano XXV, p. 182.

${ }^{26}$ Cf. Paolo Ungari, Alfredo Rocco e l'ideologia giuridica del fascismo, Biblioteca de Storia Contemporânea, Brescia, Morcelliana, 1963. Ungari integrou juntamente com Guido Astuti; Carlo Ghisalberti; Camilo Giardina e António Marongiu o conselho científico da Rivista de Storia del Diritto Contemporâneo, dirigida por Claudio Schwarzenberg, aparecida em 1976.

27 Cf. Michael Stolleis, The Law Under the Swastika, Studies on Legal History in Nazi Germany, Trad. Thomas Dunlap, Int. de Moshe Zimmermann, Chicago/Londres, University of Chicago Press, 1998, que recolhe diversos estudos do autor, entre os quais, "Community and national Community (Volksgemeinshaft): Reflections on Legal Terminology under National Socialism», de 1972.

28 Cf. Bibliografia Orientativa del Fascismo (Dir. Renzo De Felice), I Fatti Della Storia, Strumenti di lavoro, 1, Roma, Bonacci Editore, 1991, p. 207. Naturalmente que ao longo da Bibliografia se encontram referenciados estudos cujos temas são sobretudo jurídicos (v.g. corporativismo, organização do Estado, relaçôes com a Igreja) ou intimamente relacionados com o jurídico. 
vel consistência dos contributos dedicados aos séculos XIX e XX» ${ }^{29}$. Essa nova orientação teve no jus-filósofo Giovanni Tarello, através especialmente dos Materiali per una Storia della Cultura Giuridica ${ }^{30}$, cuja publicação iniciou em 1971, um dos seus qualificados intérpretes, e no Centro di Studi per la Storia del Pensiero Giuridico Moderno um notável meio de irradiação de novas orientações metodológicas e temáticas, cuja influência científica ultrapassou largamente as fronteiras de Itália. Já prestes a abandonar a direcção do Centro, que fundara há cerca de três décadas, Grossi dá testemunho do seu interesse pela história jurídica da contemporaneidade ao dedicar os Quaderni Fiorentini, editados em 1999, ao tema: "Continuità e transformazione: la scienza giuridica italiana tra fascismo e reppublica» ${ }^{31}$, renovando-o, no ano seguinte, com a publicação da obra Scienza giuridica italiana, un profilo storico $1860-1950^{32}$.

A figura de Alfredo Rocco, um dos mais qualificados protagonistas da conquista do Estado e legislador emblemático do fascismo, tem inspirado um numeroso conjunto de autores ${ }^{33}$, A organização judiciária, o direito processual civil e penal, a legislação laboral, a pena de morte, a codificação civil de 1942, as relações do Estado com a Igreja etc., têm vindo a ser objecto de atenção de historiadores e juristas historiadores $^{34}$.

${ }^{29}$ Cf. Aldo Mazzacane, «Tendenze attuali della storiografia giuridica italiana sull'età moderna e contemporânea", in Scienza e Politica, 6, 1992, p. 17.

30 Cf. Materiali Per Una Storia Della Cultura Giuridica, raccolti da Giovanni Tarello, Instituto di Filosofia del Diritto della Università di Genova, Volume I/1971, Società Editrice Il Mulino, passaria a publicação semestral a partir de 1979, sendo actualmente editada no âmbito do "Dipartimento di Cultura Giuridica Giovanni Tarello, Sezione di Filosofia e Sociologia del Diritto» da Universidade de Génova. Sobre o autor e a sua obra, cf. L'Opera di Giovanni Tarello nella cultura giuridica contemporanea, a cura di Silvana Castignone, Temi e discussioni, Bolonha, Il Mulino, 1989.

31 Cf Quaderni Fiorentini per la storia del pensiero giuridico moderno, 28 (1999) Continuità e transformazione: la scienza giuridica italiana tra fascismo e reppublica, 2 Tomos, Milão, Giuffrè Editore.

32 Cf. Paolo Grossi, Scienza Giuridica Italina, Un Profilo Storico, 1860-1950, Milão, Giuffrè Editore, 2000. Correspondendo a idêntico interesse, Luigi Ferrajoli, La cultura giuridica nell'Italia del Novecent, Roma-bari, Editori Laterza, 1999, que corresponde à segunda versāo ampliada da colaboração do autor no volume La cultura italiana del novecento para a Enciclopedia del Sapere (1996).

33 Além do já citado Paolo Ungari, Alfredo Rocco..., Alessandro Barbera, Nazione e Stato in Alfredo Rocco, La Storia, Sveva editrice, 2001; Rocco D'Alfonso, Construire lo Stato Forte, Politica, diritto, economia in Alfredo Rocco, Presentazioni Arturo Colombo, Milão, FrancoAngeli Storia, 2004; Gennaro Malgieri, Alfredo Rocco e le idee del suo tempo, I libri di Percorsi, Roma, Editorial Pantheon, 2004 e Saveri Battente, Alfredo Rocco, Dal Nazionalismo al Fascismo, Milão, FrancoAngeli, 2005. Ainda, Alfredo Rocco, Discorsi parlamentari, Con un sagio di Giuliano Vassali, Senato della Republica, Archivio Storico, Roma, Il Mulino, 2005.

34 Cf., v.g. Gian Carlo Jocteau, La magistratura e i conflitti di lavoro durante il fascismo, 1926-1934, Prefazione di Nicola Tranfaglia, Milão, Feltrinelli Editore, 1978; Raffaele Teti, Codice Civile e Regime Fascista, Sull'Unificazione del Diritto Privato; Milão, Dott. A. Giuffrè Edotore, 1990; Franco Cipriani, Storie di Processalisti e di Oligarchi, La procedura civile nel Regno D'Italia (1866-1936), Per la storia del pensiero giuridico moderno, 38, Milão, Giuffrè Editore, 1991; Giovanni Tessitore, Fascismo e pena di morte, Consenso e informazione, Collana di Diritto e Società, Milão, FrancoAngeli, 2000 e Orazio Abbamonte, La Politica Invisibile, Corte di Cassazione e magistratura durante il Fascismo, Milāo, Giuffrè Editore, 2003. 
O fim da época franquista em Espanha abriu passo a uma incessante actividade publicística histórica. Sobre o direito nesse tempo é possível referenciar importantes publicações, da pena de historiadores do direito, mas também de historiadores não juristas, como é o caso, a título de exemplo, de: Una Milicia de la Justicia. La Política Judicial del Franquismo (1936-1945) da autoria de Mónica Lanero Táboas ${ }^{35}$. Diversas monografias provenientes dos domínios jurídico-históricos e filosóficos têm permitido aprofundar o conhecimento de autores como Álvaro D’Ors ${ }^{36}$, Luño Peña ${ }^{37}$, Francisco Javier Conde ${ }^{38}$, Legaz Lacambra ${ }^{39}$ e Castan Tobeñas ${ }^{40}$, entre muitos outros ${ }^{41}$, cujo pensamento jurídico, filosófico e político influenciou a ditadura espanhola.

Mais recentemente, já no quadro da chamada «Lei da Memória Histórica» — que devo dizer constitui um extraordinário objecto de reflexão histórica e jurídica ${ }^{42}$ —, têm-se multiplicado as publicações, de valor muito diverso, é facto, mas úteis no seu conjunto para o conhecimento da realidade jurídica da II República e do Franquismo, sem esquecer a da guerra civil, designadamente nos planos judiciário ${ }^{43}$ e $_{\text {prisional }}{ }^{44}$.

35 Cf. Mónica Lanero Táboas, Una Milicia de la Justicia. La Política Judicial del Franquismo (1936-1945), Madrid, Centro de Estudios Constitucionales, Madrid, 1996. Anterormente e para a mesma época, Juan Cano Bueso, La Politica Judicial del Regimen de Franco (1936-1945), Madrid, Centro de Publicaciones, Secretaria General Tecnica, Ministero de Justicia, 1985.

36 Cf. Rafael Domingo, Álvaro D’Ors, Una Aproximacion a su Obra, The Global Law Collection, Thomson/Arazadi, Navarra, 2005.

37 Maria Concepción Gimeno Presa, La Filosofia Jurídica de Enrique Luño Peña, Madrid, Editorial Tecnos/Fundacion Cultural Enrique Luño Peña, 2000.

38 Cf. José Antonio López García, Estado y Derecho em el Franquismo, El Nacionalsindicalismo: F. J. Conde y Luis Legaz Lacambra, Madrid, Centro de Estudios Constitucionales, 1996.

39 Idem. Ainda, AAVV, Luis Legaz Lacambra: figura y pensamiento, Maestros Complutenses de Derecho, 1, Madrid, Facultad de Derecho, Servicio de Publicaciones, 1993 e Jesus P. Rodriguez, Filosofia Política de Luis Legaz Lacambra, Prólogo de Luis Garcia San Miguel, Madrid, Marcial Pons, 1997.

40 Cf. AAVV, El pensamiento juridico de Castan Tobeñas: jornadas de homenaje en el centenario de su nacimiento, Evaristo Palomar Maldonado, (ed.), Madrid, Universidad Pontificia de Comillas, 1991.

${ }^{41}$ Revestem-se de interesse, sobretudo pelas visōes alargadas, as obras de Ricardo Garcia Manrique, La filosofia de los derechos humanos durante el franquismo, Madrid, Centro de Estúdios Constitucionales, 1996 e de Benjamín Rivaya, Filosofia de Derecho y primer franquismo (1937-1945), El Derecho y la Justicia, Madrid, Centro de Estudios Constitucionales, 1998.

42 Sugestiva das problemáticas implicadas e da sua importância revela-se a obra colectiva: Derecho y Memoria Histórica, Edición de José Antonio Martín Pallí y Rafael Escudero Alday, Madrid, Editorial Trotta, 2008.

43 Cf. v.g., Pascual Marzal Rodriguez, Magistratura y República, El Tribunal Supremo (1931-1939), Valencia, E.P.D., 2005; Manuel Álvaro Dueñas, "Por ministerio de la ley y voluntad del Caudillo", La Jurisdicción Especial de Responsabilidades Politicas (1939-1945), Prólogo Marta Bizcarrondo, História de la Sociedad Política, Madrid, Centro de Estudios Politicos y Constitucionales, 2006; Raúl C. Cancio Fernandez, Guerra Civil y Tribunales: De los Jurados Populares a la Justicia Franquista (1936-1939), Prólogo de José Antonio Martín Pallín, Cáceres, Universidad de Extremadura, 2007; Eduardo Barriobero y Herrán, El Tribunal Revolucionario de Barcelona, 1936-1937, seguido de Eduardo Barrobero y Herrán "Nada menos que todo un hombre» de Jacinto Torhyo, Introd. De Eduard Masjuan, Sevilha, Espuela de Plata, 2007 e Juan José del Águila, El TOP, La represión de la libertad (1963-1977), Prologo de Gregorio Peces-Barba, Madrid, Planeta Historia y Sociedad, 2001.

${ }^{4}$ Cf. v.g. Iván Heredia Urzáiz, Delitos políticos y orden social, Historia de la cárcel de Torrero (1928-1939), Zaragoza, Mira editores, 2005; Gutmaro Gómez Bravo, La Redención de Penas, La Formación del Sistema Penitenciario Franquista, 1936-1950, Madrid, Catarat, 2007. 
Em França é também de sublinhar a relevância crescente da investigação sobre temáticas jurídicas do século XX. Meramente a título de exemplo refiro La Justice des Années Sombres, 1940-194445, que recolhe um conjunto de contribuições entre as quais se destacam as de Catherine Fillon, Denis Salas e Jean-Louis Halpérin, e a obra colectiva dirigida por Bernard Durand, Jean-Pierre Le Crom e Alexandre Somma: Le Droit sous Vichy ${ }^{46}$, integrada nos importantes Studien zur europaischen Rechtsgeschichte.

Permito-me uma palavra sobre o Brasil, para referir a importância de estudos sobre o varguismo, no contexto do que foi designado por "corporativismo em português» 47 , e assinalar a recente edição em Porto Alegre de um estudo de história jurídico-política sobre o Supremo Tribunal Federal, que teve origem numa dissertação de mestrado apresentada à Faculdade de Direito de Coimbra ${ }^{48}$.

Em particular sobre o corporativismo nas ditaduras do sul da Europa, deve mencionar-se a obra colectiva dirigida por Aldo Mazzacane, Alessandro Somma e Michael Stolleis, editada em $2005^{49}$.

No plano dos estudos históricos comparados reveste-se do maior interesse o volume de estudos que sob a coordenação de Federico Fernández-Crehuet López e António Manuel Hespanha, foi editado sob o título: Franquismus und Salazarismus: Legitimation durch Diktatur? ${ }^{50}$.

Quero crer que entre nós o centenário da implantação da República pode constituir um acontecimento dinamizador de vários saberes para que se aprofunde o conhecimento dum período crucial da nossa história contemporânea, incompatível com a rigidez de fronteiras temáticas. Sendo assim, não é possível que se dispense no âmbito desses estudos a dimensão jurídico-política da situação saída do 5 de Outubro de 1910. A sua ponderação revela-se essencial ao entendimento da origem, evolução e factores de crise da proposta política que esteve na base do modelo constitucional de 1911. Há nesse sentido muito e importante trabalho a realizar, isto porque, não obstante contribuições valiosas que vêm sendo dadas à história da I República, ela é

45 Cf. La Justice des Années Sombres, 1940-1944, Préface de Pierre Truche, Paris, La Documentation Française, 2001.

46 Cf. Le Droit sous Vichy (Bernard Durand, Jean-Pierre Le Crom, Alessandro Soma, eds.), Das Europa der Diktatur, Frankfurt am Main, Vittorio Klostermann, 2006.

47 Cf. O Corporativismo em Português, Estado, Política e Sociedade no Salazarismo e no Varguismo, António Costa Pinto e Francisco Carlos Palomanes Martinho (organizadores), Lisboa, Imprensa de Ciências Sociais, 2008. Ainda, com amplas referências ao caso português, Progetti corporativi tra le due guerre mondiali, a cura de Matteo Pasetti, Quaderni del Dipartimento di Discipline Storiche, Università di Bologna, Roma, Carocci Editore, 2006.

48 Cf. Marcelo Paiva dos Santos, A História não contada do Supremo Tribunal Federal, Porto Alegre, Sérgio António Fabris Editor, 2009.

49 Cf. Korporativismus in den sudeuropaischen Diktaturen. Il corporativismo nelle dittature Sudeuropee (Aldo Mazzacane, Alessandro Somma, Michael Stolleis Eds), Das Europa der Diktatur, Frankfurt am Main, Vittorio Klostermann, 2005.

50 Cf. Franquismus und Salazarismus: Legitimation durch Diktatur?(Federico Fernández-Crehuet López e António Manuel Hespanha Eds), Das Europa der Diktatur, Frankfurt am Main, Vittorio Klostermann, 2008 . 
ainda em vastos domínios desconhecida, ou mal conhecida. E penso no direito, e nas importantes lacunas que importa colmatar na historiografia «jurídica» dessa época.

Fundamental será que o sentimento comemoracionista — que partilho —, sirva a dinamizar a investigação — naturalmente num quadro multidisciplinar —, que não obscureça a verdade histórica, «um banho de realidade forte» — para utilizar palavras de Vieira de Almeida numa reflexão sobre o significado e função da história ${ }^{51}$ — que não consinta pré-conceitos nem clichés os quais, em não poucos casos, têm contribuído para visôes desfocadas da I República, algumas mesmo intoleráveis, no plano da ciência e da cidadania.

\section{E termino:}

Sem prejuízo do respeito pelas autonomias conceptuais e metodológicas determinadas pelos particularismos dos objectos de estudo de historiadores e juristas historiadores, não se vê que melhor e mais profícuo caminho possa ser trilhado senão aquele que se trace a partir da máxima convergência possível, no sentido de definitivamente colocar de lado perspectivas redutoras que são factores de desarmonia, onde só a sintonia é verdadeiramente criadora.

51 Vieira de Almeida, História (Significado e Função), These para o $4 .^{\circ}$ anno do Curso Superior de Letras - Secção de Geographia e História - 1910, Coimbra, Imprensa da Universidade, 1911, p. 71. 

Série

Documentos

Imprensa da Universidade de Coimbra

Coimbra University Press

2010

- U

C • 